\title{
Comparing wave heights simulated in the Black Sea by the SWAN model with satellite data and direct wave measurements
}

\author{
Stanislav Myslenkov ${ }^{1,2}$ and Anna Chernyshova ${ }^{3,4}$ \\ Received 8 October 2016; accepted 11 October 2016; published 3 November 2016.
}

The results of wave simulation in the Black Sea using the SWAN spectral wave model and wind forcing data from the NCEP/CFSR reanalyze are presented in this paper. The calculations were done using the special unstructured mesh with spatial resolution of $10 \mathrm{~km}$ in the open sea and $200 \mathrm{~m}$ in the Tsemes Bay. The assessment of the wave simulation accuracy was performed on the basis of the satellite altimetry data and direct wave measurements in the shallow water. When comparing the calculated significant wave height with observational data the correlation equaled 0.8 , while the root mean square error equaled 0.3. The comparison of simulation results and satellite data also showed good correlation. KEYWORDS: Black Sea; Tsemes Bay; wind waves; wave modeling; SWAN; unstructured mesh; satellite altimetry.

Citation: Myslenkov, Stanislav and Anna Chernyshova (2016), Comparing wave heights simulated in the Black Sea by the SWAN model with satellite data and direct wave measurements, Russ. J. Earth. Sci., 16, ES5002, doi:10.2205/2016ES000579.

\section{Introduction}

There are many ways of using modern wind-wave models in order to study the wave climate and wave forecast. Scientists often use the third-generation spectral wave models, like WAM, Wave watch 3 and SWAN. The main strategies of wave simulation in the open sea and coastal zones are shown in [Rusu, 2011]. The work [Roland and Ardhuin, 2014] describes several parameterizations for coastal wave models. Wind forcing from the NCEP/NCAR reanalysis (1948-2010) and the SWAN model used in [Arkhipkin et al., 2014 to develop the wave database of the Black Sea. However, there are few quality estimates of the model presented in this paper. There are several publications giving more detailed model quality estimation based on direct wave measurements provided by the NATO TU-WAVES project [Akpinar et al., 2012 Akpinar and Ponce de León, 2016. Kos'yan et al., 1998 Van Vledder and Akpinar, 2015]. In work [Akpinar et al., 2012 the results of SWAN model are based on the Era-interim reanalysis. Comparison of model results and wave buoy measurements has shown that the model under-

\footnotetext{
${ }^{1}$ Lomonosov Moscow State University, Faculty of Geography, Moscow, Russia

${ }^{2}$ Hydrometeorological Research Centre of the Russian Federation, Marine forecast division, Moscow, Russia

${ }^{3}$ School of Mechanical Engineering Tel-Aviv University, TelAviv, Israel

${ }^{4}$ Southern Branch of P. P. Shirshov Institute of Oceanology, Russian Academy of Sciences, Gelendzhik, Russia
}

Copyright 2016 by the Geophysical Center RAS.

http://elpub.wdcb.ru/journals/rjes/doi/2016ES000579-res.html estimates wave height values. In the works [Akpinar and Ponce de León, 2016. Van Vledder and Akpinar, 2015 different reanalysis were compared, while the main conclusion was that the NCEP/CFSR reanalysis provided better result (the root mean square error (RMSE) - 0.4 and correlation 0.88). Comparison of the significant wave height (SWH) and satellite data resulted in RMSE and correlation equalling 0.4 and 0.78 respectively. It is very important to study extreme weather events, for instance, in the work [Bukhanovskij et al., 2009 WaveWatch 3 and Era-interim reanalysis were used for retrospective study of a great storm in November 2007, when significant wave height was up to $8-9 \mathrm{~m}$. The work [Valchev et al.,2012 shows the peculiarities of wave regime and its dependence on climatic changes. The wave monitoring system based on the radar station is presented in the work [Ivonin et al., 2016. The radar data were compared with the results of the SWAN model and the quality of simulation was recognized as high. The Russian atmospheric-wave model was also used successfully for wave simulation in the Black sea [Kabatchenko et al., 2001]. The characteristics of wave regime in the Black Sea [Polonsky et al., 2011] were restored using the SWAN model.

The SWAN model based on unstructured mesh with spatial resolution 50-100 m was successfully used for the Kerch strait [Stoliarova and Myslenkov, 2015]. This model is often used for estimation of wave energy potential [Arhipkin et al., 2015, because its data output allow us to calculate wave energy supply of a water area. Often in studies regular computation grids are used but at the same time, it becomes more popular and more accessible to use unstructured grids for coastal areas [Rusu, 2011, Stoliarova and Myslenkov, 2015 Zijlema, 2010]. Thus, there is a need to estimate SWAN 


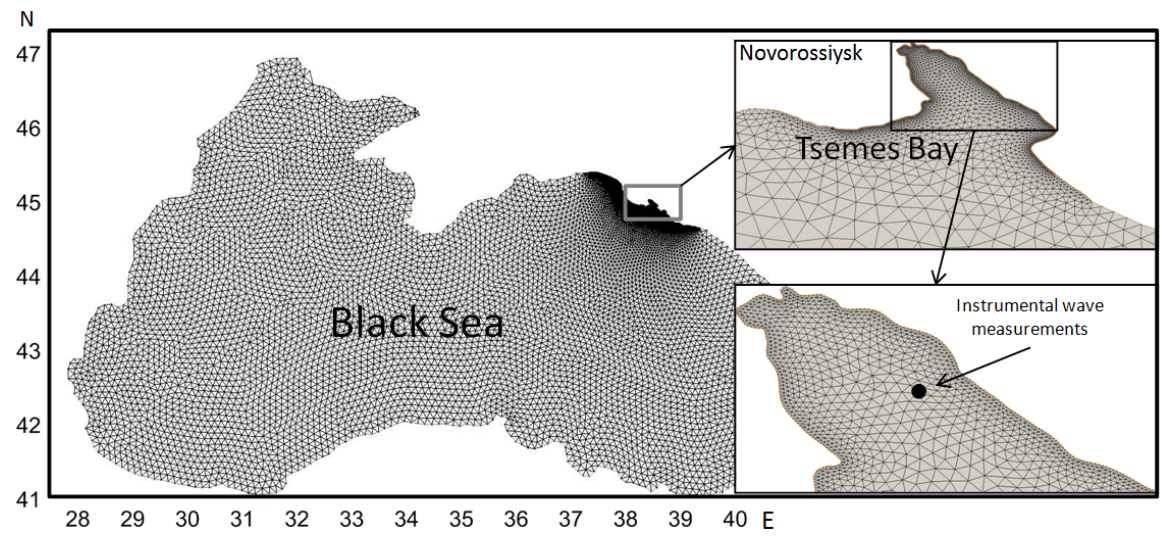

Figure 1. Unstructured mesh for SWAN model of the Black Sea and the Tsemes bay. The black circle stands for the place where instrumental wave measurements were conducted.

model quality with using unstructured grid for the Black sea.

The operative wave forecast in the Black Sea is realized in the Hydrometeorological Centre of Russia by means of WW3 model [Zelen'ko et al., 2014]. The model has the spatial resolution of $9 \mathrm{~km}$ and it works on the GFS forcing. The model quality estimations was carried out on the basis of the satellite data, and the results of the tests were recognized as satisfying ( $\mathrm{RMSE}=0.36, \mathrm{R}=0.87$ ).

All statistical parameters of wind waves in the Black sea can be found in the shipping registrar [Lopatuhin et al., 2006, where the SWAN model was used and the assessments showed good coincidence with the observation details.

Another important task is to analyze accuracy of the model at different depths. When wind waves reach shallow water wave breaking starts; in addition bottom friction, refraction and other processes take place. There is a critical shortage of direct observation data for the Black Sea. One of the most accessible data sources is satellite altimetry, however it's impossible to apply it to shallow water.

Once we received direct wave measurement data for the Tsemes Bay we decided to use it in order to measure the quality of the SWAN model for shallow water and also to test its accuracy as applied to deep water using satellite data.

\section{Description of Wave Measurements}

Instrumental wave measurements were completed with the water level laser sensor Riegl LD90-3200HiP (3 Hz, accuracy $= \pm 2 \mathrm{~cm})$ [Ivonin et al.,2016] Myslenkov et al.,2016] at the end of the "Sheskharis" pier in the Themes Bay at the depth of $20 \mathrm{~m}$ (Figure 1). The data on SWH over the period of three years (2010-2012) with 15 minute interval were provided by Alexey Ponomarev (Hydromet Office at Novorossiysk). Some of the data processing results are represented in [Myslenkov and Arkhipkin, 2013. Myslenkov et al., 2016.

Furthermore, for the year 1996 we used the data from DATAWELL "Directional Waverider buoy". It was set up near Gelendzhik (location: 37.9783 E, 44.5075 N, installed at $85 \mathrm{~m}$ ). It measures the SWH up to $40 \mathrm{~m}$ (with $1 \mathrm{~cm}$ accuracy) and wave period (1.6-30 seconds). Recorded data are transferred from the buoy to the receiving device every 3 hours, but the interval drops to 1 hour when the SWH is $1.5 \mathrm{~m}$ or more [Kos'yan et al., 1998 .

Today the satellite altimetry data are essentially a source of information on a global scale that can be used in a variety of ways: from major ocean currents monitoring to studies of wind and swell waves and their interaction with the wind. The satellite altimetry data are used for wave climate studies [Chelton and McCabe, 1985]. In [Saleh Abdalla et al., 2011] triple collocation method was used for estimating accuracy of the altimetry data, that are also used for development of mathematical models for wind speeds [Chelton and McCabe, 1985. Goldhirsh and Dobson, 1985 Saleh Abdalla, 2007] and wave periods [Badulin, 2014 Gommenginger et al., 2003 Mackay et al., 2008, Quilfen et al., 2004.

We created a full database of wind waves parameters in the Black and the Azov seas for the period from 1985 to 2014 with altimetry measurements (Figure 2 . This regional database of altimetry measurements includes the L2P data provided by the European Space Agency as part of the Globwave initiative (http://globwave.ifremer.fr). The database contains 21074 tracks with 875010 points in total. Measured wave height and backscatter coefficients in Ku-band (wave length range $2.5-1.67 \mathrm{~cm}$, frequency range $12-18 \mathrm{GHz}$ ) and C-band (wavelength range $7.5-3.75 \mathrm{~cm}$, frequency range 4$8 \mathrm{GHz}$ ) are provided by Globwave and are averaged over 1 second sampling interval (appr. $6 \mathrm{~km}$ in space). The data can be used for retrieving the key parameters of wind-sea interaction: wind speed near sea surface and wave periods. While gathering data for the Black Sea, the Globwave quality flags were taken into account. Two quality variables from the Globwave project were used - SWH and backscatter coefficient quality flags. These variables separate recorded which were likely to be good from those, which were most likely bad. Those likely to be good were further divided into two groups: the ones that were generally acceptable and the certainly good ones. The data validation was based on the several handbooks and publications, together with some unpublished methods used by Satellite Observing Systems Ltd. (http://globwave.ifremer.fr).

At the next step additional data filtering algorithms were applied, according to the following criteria, empirically based 


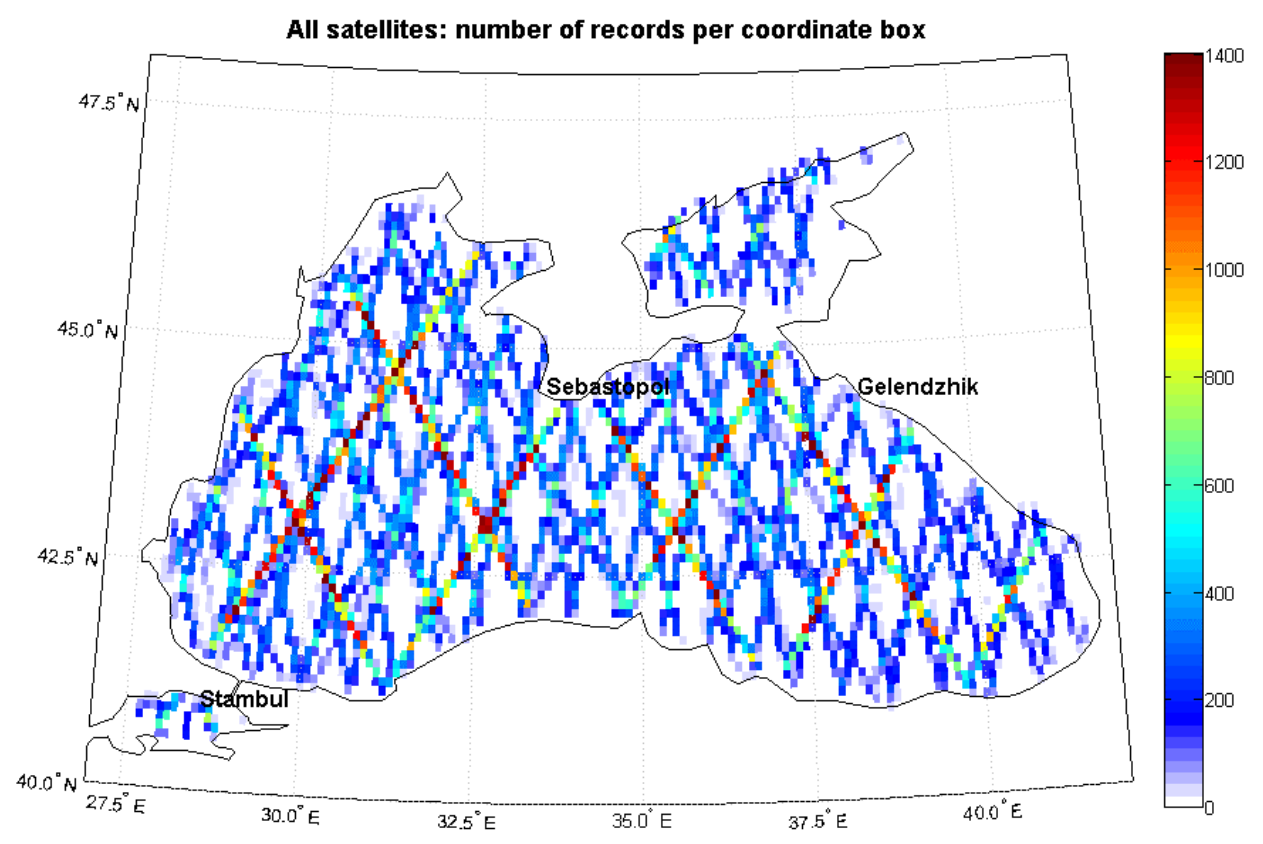

Figure 2. Density of altimetry points on the Black Sea map.

on practice [Saleh Abdalla et al., 2011]. Due to these, some invalid data was rejected: 2001-2005 years of Topex; 20062008 years of GFO; records with standard deviation of SWH in excess of $1 \mathrm{~m}$; records with standard deviation of the range in excess of $0.2 \mathrm{~m}$; records with square off-nadir angles larger than $0.4\left({ }^{\circ}\right)^{2}$ and those lower than $0.2\left(^{\circ}\right)^{2}$. Finally, good quality data set contains 678978 points in total.

We used data from Envisat, Jason 1, Jason 2 satellites for the year 2010-2011 and ERS-1, ERS-2 and Topex for the year 1996 .

\section{Wave Model Configuration}

In wind wave hindcast and forecast researchers often use spectral wind-wave models such as WAM (Wave Modelling), WW3 (WaveWatch 3), SWAN and STWAVE (Steady State Wave Model). The results of wave modelling strongly depend on the choice of the wind forcing data-in and computation grid [Akpinar et al., 2012 Akpinar and Ponce de León, 2016 Arkhipkin et al., 2014.

Our wave hindcast is based on the SWAN (Simulating Waves Near Shore) spectral wave model [Booij et al., 1999 . SWAN Team, 2007. This model successfully simulates the parameters of wind waves in the open sea and coastal areas [Akpinar et al., 2012, Akpinar and Ponce de León, 2016. Arkhipkin et al., 2014 Lopatuhin et al., 2006. Medvedeva et al., 2015 Myslenkov and Arkhipkin, 2013. It is important that the SWAN model successfully simulates sea waves in the shallow water as well because depth of Tsemes Bay essentially varies between 20 and $40 \mathrm{~m}$.

In our implementation of SWAN model we used the following configuration: GEN3, KOMEN (cds2 $=2.36 e-5$, stpm $=3.02 e-3)$, Quadrupl, Triad, Breaking constant $($ alfa $=1.0$, gamma $=0.73)$ and Friction Jonswap constant $(c f=0.067)$. This is default configuration for SWAN model and we used it because we have successful wave modelling with this settings [Arkhipkin et al., 2014. Arhipkin et al., 2015. Medvedeva et al., 2015 Myslenkov and Arkhipkin, 2013 Myslenkov et al., 2016 Stoliarova and Myslenkov, 2015. Toropov et al., 2012 and we had no physical justification for changing any of the coefficients. Scientists have used this model in several investigation and its detailed description and technical summary are present in publications [Akpinar et al., 2012 Akpinar and Ponce de León, 2016 Booij et al., 1999 SWAN Team, 2007. Van Vledder and Akpinar, 2015.

For hindcast wave modelling we used wind data from NCEP Climate Forecast System Reanalysis (http://rda.ucar.edu, [Saha, 2014]), which provided $\sim 0.3^{\circ}$ and $\sim 0.2^{\circ}$ spatial resolution for years 2010 and 2011-2012 respectively with 1 hour interval. Also for estimation of reanalysis quality, we used wind data from weather stations located in Anapa and Novorossiysk, with 3 hour interval.

Computational unstructured grid was made by means of Surface modelling System (Aquaveo). Depth values for the Black Sea and the Tsemes Bay in particular were digitized from navigation maps with spatial resolution up to $100 \mathrm{~m}$ in coastal zone. The similar methods were described in several publications [Myslenkov and Arkhipkin, 2013 Myslenkov et al., 2016. Stoliarova and Myslenkov, 2015 Zijlema, 2010. Thus, we have got an unstructured mesh that contains 8443 nodes with spatial resolution changing from $10 \mathrm{~km}$ in the open sea to $200 \mathrm{~m}$ in the Tsemes Bay (Figure 1). This grid has low resolution and a very simple coast line everywhere 

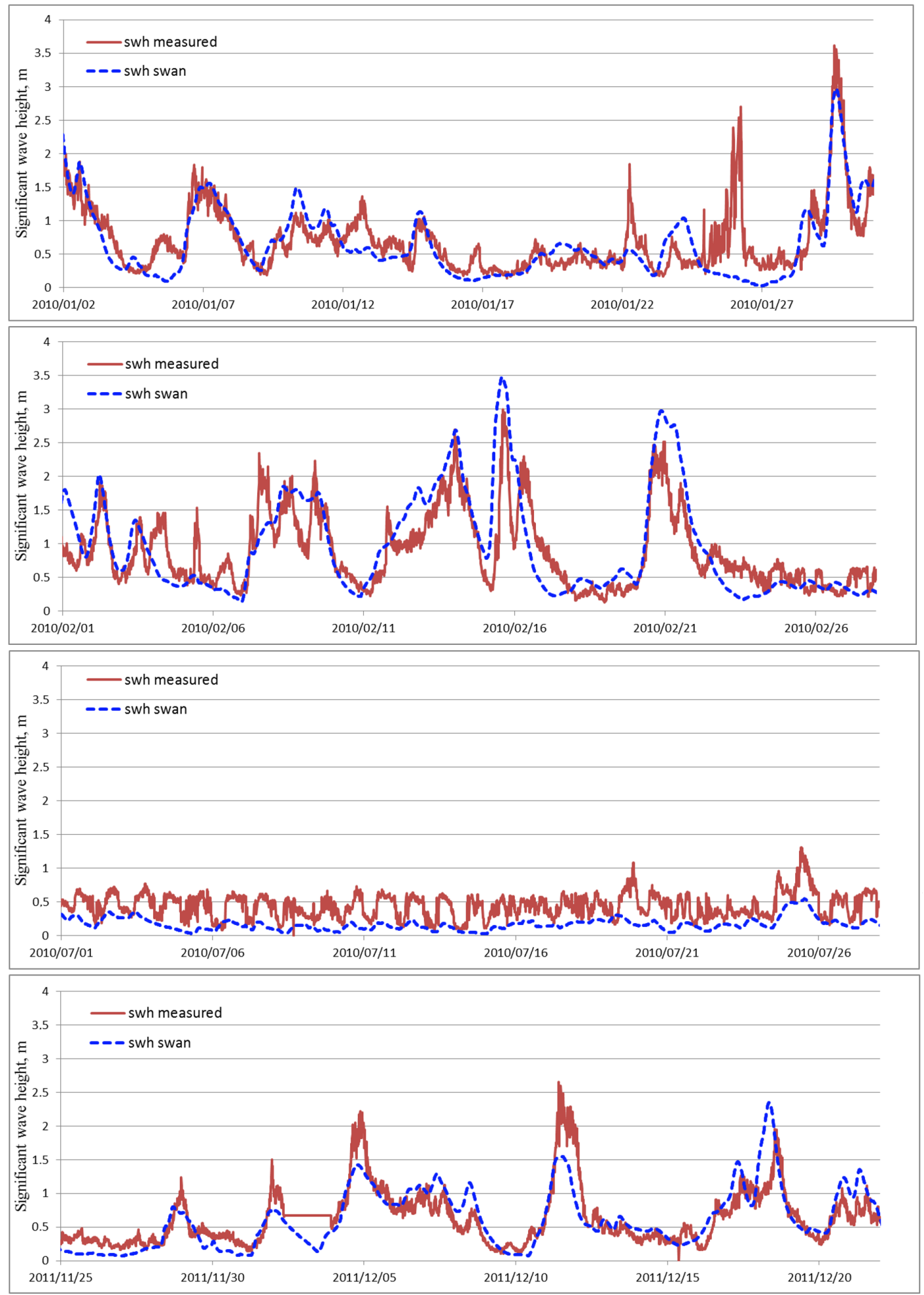

Figure 3. Comparison of significant wave height $(\mathrm{m})$ measured in the Tsemes Bay and results of the SWAN model.

except the area near the Tsemes bay (Novorossiysk). It allowed us to get high spatial resolution with a small number of nodes.

The SWAN model was used for wave simulation for 2010
2012 with 15 minutes time interval. Then, we checked the quality of simulation as compared to the instrumental wave measurements in the Tsemes Bay (Figure 3). There were few episodes when significant wave height was more than 
Table 1. Statistical Analysis Results of Model Performance in the Shallow Water of the Tsemes Bay

\begin{tabular}{|c|c|c|c|c|c|c|c|c|c|c|c|c|}
\hline \multirow[b]{2}{*}{ Month } & \multicolumn{4}{|c|}{2010} & \multicolumn{4}{|c|}{2011} & \multicolumn{4}{|c|}{2012} \\
\hline & $\mathrm{R}$ & Bias & RMSE & SI & $\mathrm{R}$ & Bias & RMSE & SI & $\mathrm{R}$ & Bias & RMSE & SI \\
\hline January & 0.78 & -0.06 & 0.38 & 0.52 & 0.81 & -0.12 & 0.26 & 0.53 & 0.83 & -0.04 & 0.24 & 0.38 \\
\hline February & 0.85 & 0.09 & 0.43 & 0.51 & 0.92 & -0.19 & 0.30 & 0.49 & 0.62 & -0.01 & 0.32 & 0.63 \\
\hline March & 0.71 & -0.17 & 0.31 & 0.48 & 0.91 & -0.12 & 0.20 & 0.39 & 0.88 & -0.14 & 0.31 & 0.47 \\
\hline April & 0.54 & -0.15 & 0.25 & 0.56 & 0.87 & -0.17 & 0.31 & 0.46 & 0.85 & 0.01 & 0.29 & 0.56 \\
\hline May & 0.35 & -0.15 & 0.23 & 0.58 & 0.26 & -0.18 & 0.24 & 0.68 & 0.61 & -0.14 & 0.21 & 0.60 \\
\hline June & 0.53 & -0.23 & 0.30 & 0.66 & 0.78 & -0.28 & 0.32 & 0.62 & 0.58 & -0.23 & 0.28 & 0.69 \\
\hline July & 0.51 & -0.30 & 0.33 & 0.71 & 0.41 & -0.31 & 0.34 & 0.74 & 0.57 & -0.29 & 0.34 & 0.71 \\
\hline August & 0.30 & -0.28 & 0.31 & 0.67 & 0.44 & -0.28 & 0.31 & 0.68 & 0.52 & -0.26 & 0.31 & 0.66 \\
\hline September & 0.60 & -0.17 & 0.22 & 0.56 & 0.51 & -0.22 & 0.24 & 0.68 & 0.13 & -0.24 & 0.27 & 0.72 \\
\hline October & 0.72 & -0.1 & 0.22 & 0.53 & 0.73 & -0.13 & 0.21 & 0.50 & 0.87 & -0.15 & 0.23 & 0.50 \\
\hline November & 0.89 & -0.04 & 0.27 & 0.38 & 0.80 & -0.17 & 0.22 & 0.62 & 0.79 & -0.13 & 0.22 & 0.54 \\
\hline December & 0.77 & 0.08 & 0.40 & 0.58 & 0.74 & -0.01 & 0.30 & 0.48 & 0.84 & -0.06 & 0.26 & 0.45 \\
\hline Year & 0.75 & -0.12 & 0.31 & 0.56 & 0.81 & -0.17 & 0.27 & 0.57 & 0.76 & -0.15 & 0.27 & 0.57 \\
\hline $\begin{array}{l}\text { Year } \\
\text { (without period } \\
\text { April-October) }\end{array}$ & 0.81 & -0.04 & 0.34 & 0.51 & 0.83 & -0.12 & 0.26 & 0.5 & 0.81 & -0.08 & 0.26 & 0.49 \\
\hline
\end{tabular}

$2 \mathrm{~m}$, but it is a regular situation for this region [Surkova et al., 2013. Most of these occasions happened in the winter, while in the summer SWH did not exceed 1-1.5 m. In July of 2010 (Figure 3) there was noticeable periodicity of wave height changes which was caused by the breeze effect. The graphs show that the wave model results correlate strongly with instrumental wave measurements. The maximum values of SWH on the graph (that indicate storms) were simulated with error reaching $0.5-1 \mathrm{~m}$. However, we cannot say for sure that the wave model systematically underestimates measured waves because in some cases we can see good correlation between the model and instrumental measurements and sometimes even over-estimation of wave height (Figure 3).

The statistical analysis was based on wave measurements that include the period from 2010 to 2012 and contain over 100,000 records with $10-15$ minute interval.

Wave model performance estimation was based on comparison of its results and the instrumental measurements, and included the following statistical parameter:

$$
\begin{aligned}
& \mathrm{BIAS}=\frac{\sum_{i=1}^{n}\left(S w h_{\mathrm{model}, i}-S w h_{\mathrm{obs}, i}\right)}{n} \\
& \mathrm{RMSE}=\sqrt{\frac{\sum_{i=1}^{n}\left(S w h_{\text {model }, i}-S w h_{\mathrm{obs}, i}\right)^{2}}{n}} \\
& \mathrm{SI}=\frac{\mathrm{RMSE}}{\overline{S w h}_{\mathrm{obs}}}
\end{aligned}
$$

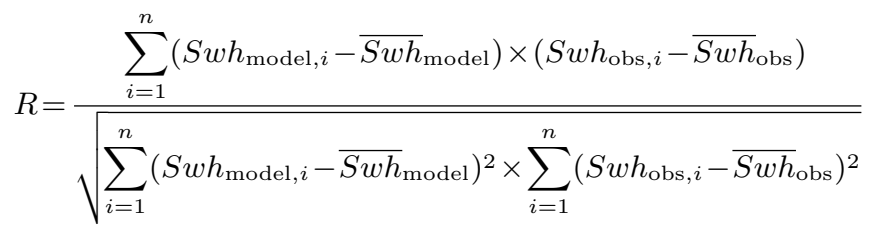

where: $S w h_{\mathrm{obs}, i}$ is the observed significant wave height, $\overline{S w h}_{\mathrm{obs}}$ is the mean value of the observed data, $S w h_{\text {model }, i}$ is the simulated significant wave height, $\overline{S w h}_{\text {model }}$ is the mean value of the simulated data, $n$ is the total number of data.

The same formulas were used for statistical analysis of wave period data.

The results of statistical analysis are presented in Table 1 It is clear that for the period from May to October the correlation is weak and there are high biases (with slight differences between various years). The main cause of these biases was that we used the wind data from CFSR Reanalysis which didn't include simulation of breeze effects. In the winter, the correlation reaches $0.75-0.85$ and bias does not exceed $-0.2 \mathrm{~m}$. If we exclude period from April to October from statistical analysis the average correlation will reach 0.8 , the RMSE and bias will equal $0.3 \mathrm{~m}$ and $-0.1 \mathrm{~m}$ respectively. Similar results were provided earlier in the studies [Akpinar et al., 2012] Akpinar and Ponce de León, 2016. Van Vledder and Akpinar, 2015. where wave model results were compared to buoy measurements on deep water. In this study, we received similar or slightly better results for more complicated conditions of shallow water.

In addition, we constructed scatter diagrams and error distribution graphs based on comparison of wave measurements and model results Figure 4. The point cloud is stretched along the median line, which seems to be a good result.

However, in 2011 and 2012 model results showed underestimation of wave height values. The analysis of error distribution showed that bias would equal zero until the wave height exceeded $2-2.5 \mathrm{~m}$. When the waves were higher than 2.5-3 m bias reached $-1 \mathrm{~m}$. The graph of the error distribution in 2012 is very different from graphs for 2010 and 2011 , because there were only few times that year when wave height reached $2.5 \mathrm{~m}$ and that was not enough for proper statistical analysis. 

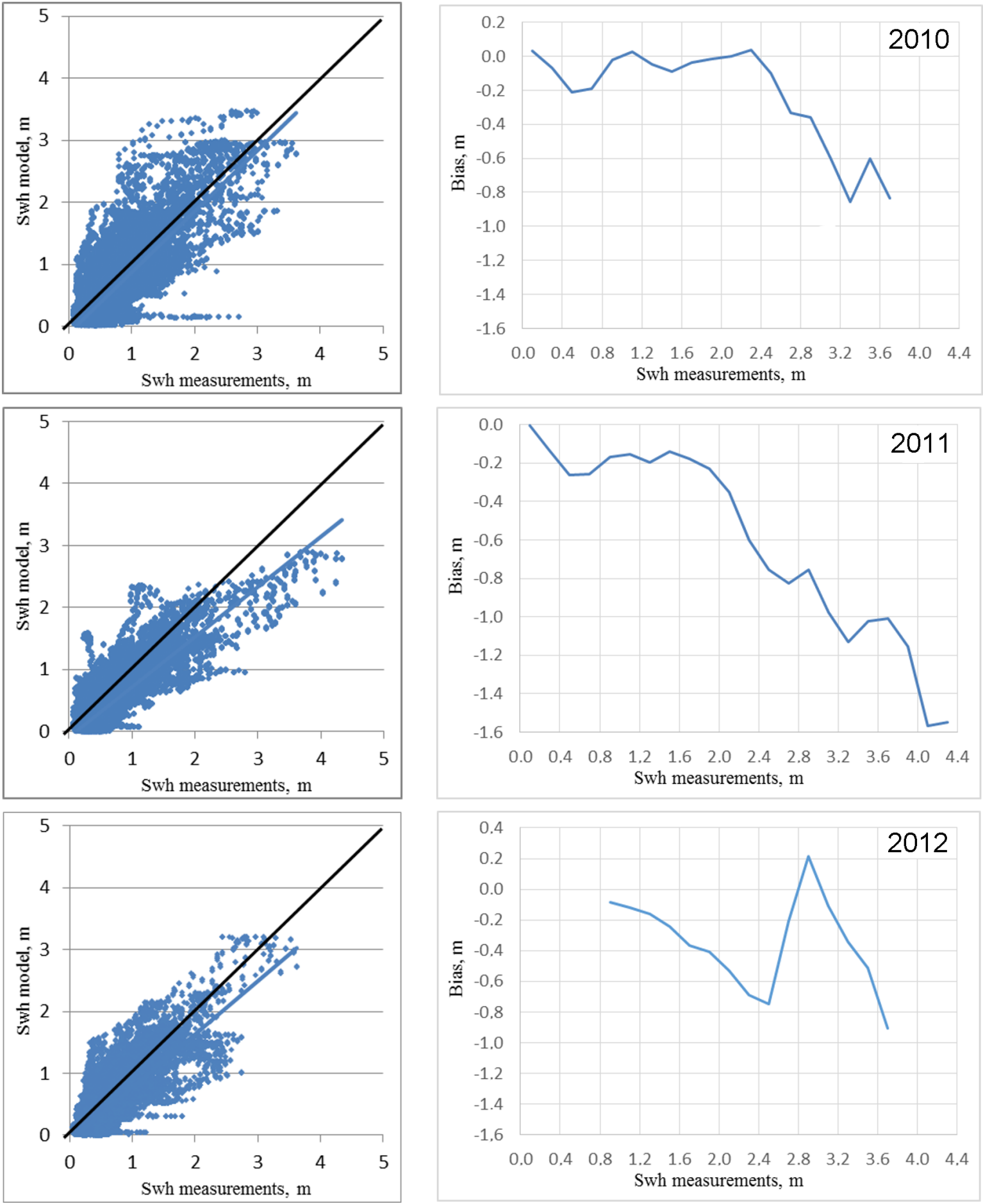

Figure 4. Scatter diagrams and error distribution graphs for 2010-2012.

In order to compare the simulation with satellite data we used the model grid points that were collocated to the altimetry points. The distance between SWAN and altimetry points did not exceed $10-12 \mathrm{~km}$. The Figure 5 present scatter diagrams of altimeter and SWAN SWH values with provision for point density. The RMSE, bias and correlation were calculated.

In whole, model results agree with satellite data in 2010 and 2011 (Figure 5a, Figure 5k). The RMSE equals $0.3 \mathrm{~m}$ for 2010 and is even less for 2011. If we look at the distribution 

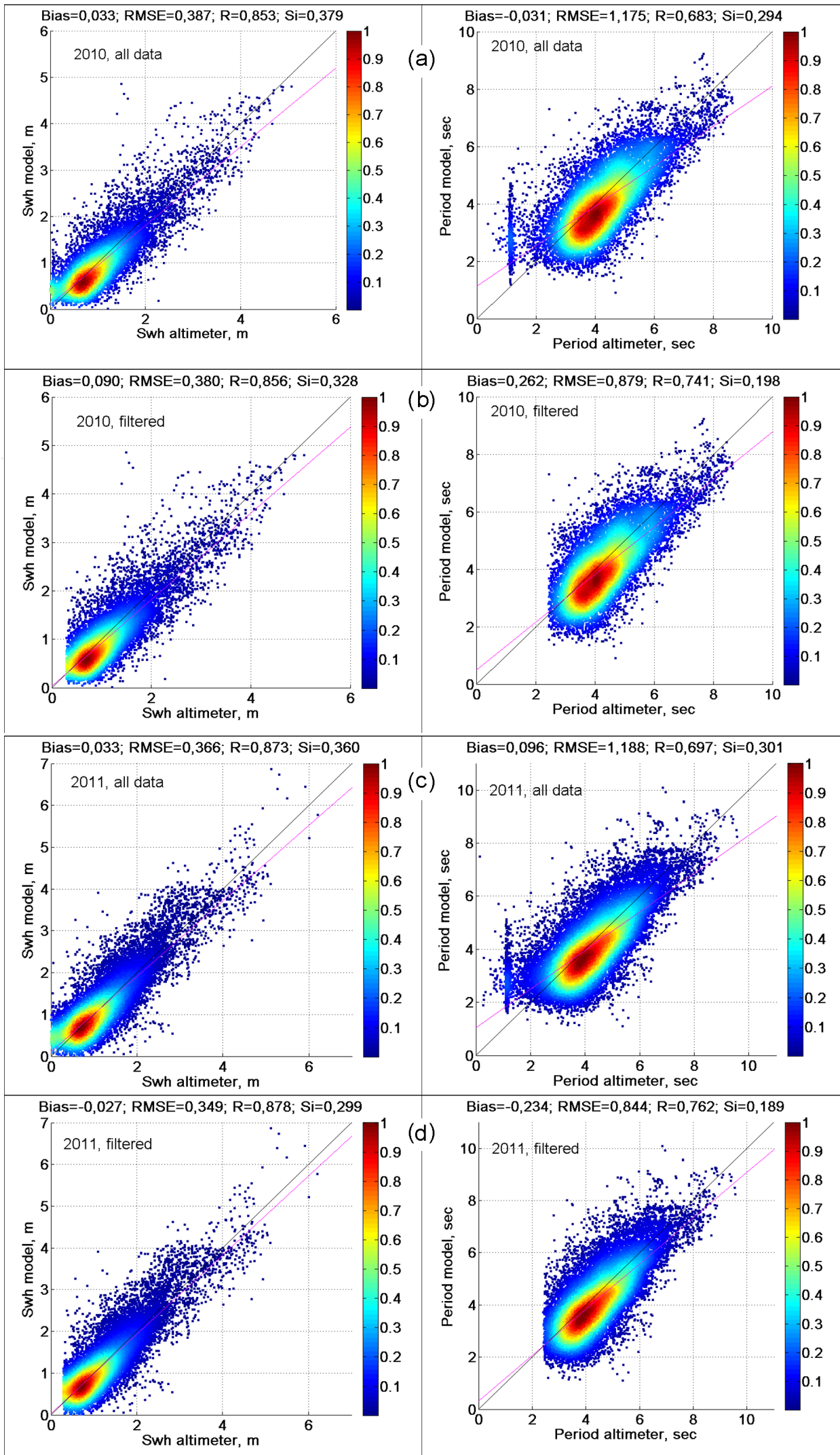

Figure 5. Comparison of SWAN and altimetry significant wave height values: a) 2010, all the data, b) 2010, after filtering out small SWH values (less than $0.3 \mathrm{~m}$ ), c) 2011, all the data, d) 2011, after filtering out small SWH values (less than $0.3 \mathrm{~m}$ ). 


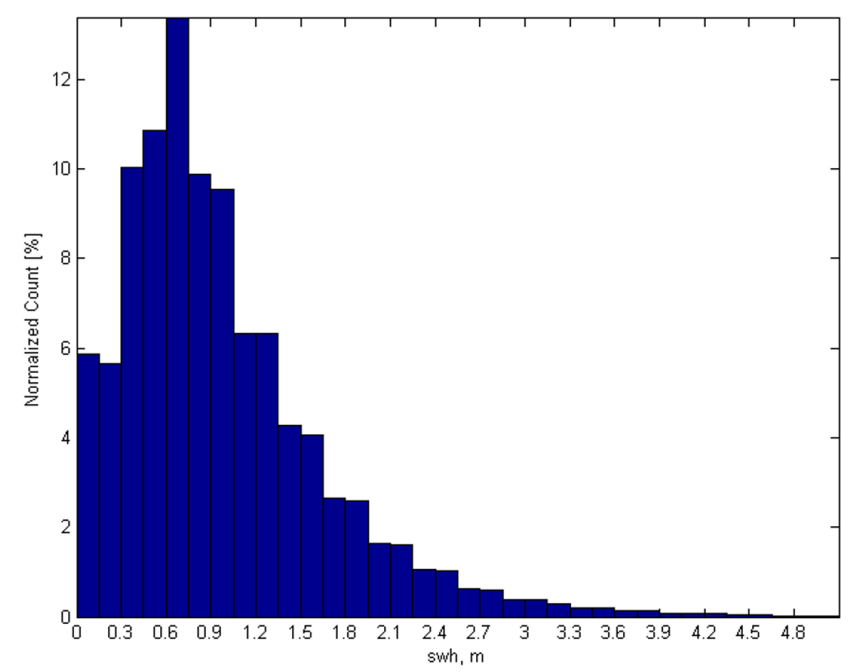

Figure 6. Distribution of SWH (altimetry data).

of data, we can see that around $12 \%$ of records have $\mathrm{SWH}$ values that are less than $0.3 \mathrm{~m}$ (Figure 6). As we know the RMSE between the buoy and altimetry data is around $0.3 \mathrm{~m}$, and accuracy of the latter is not reliable enough [Janssen et al., 2006. Therefore, it is better to remove satellite records with SWH less than $0.3 \mathrm{~m}$ because they exactly exceed its limit of accuracy. The scatter diagram for all the records shows that when SWH value is below $0.3 \mathrm{~m}$, point density starts acting poorly. This is also valid for wave period.

So, after filtering altimetry SWH values we see that satellites and SWAN data strongly correlate Figure 5p, Figure $5 \mathrm{~d}$ ). Unfortunately, due to the nature of satellite altimetry data they cannot be used in the coastal area, but we see that in deep water they can successfully serve for wave model verification.

In the work [Van Vledder and Akpinar, 2015] wave model results were compared with ERS-1, ERS-2 and Topex data. The RMSE and correlation equaled 0.41 and 0.78 respectively. Our results are slightly better supposedly, because our study included analysis of only 2 years and we used different satellite missions as well as a new version of CFSR with better resolution $\left(0.2^{\circ}\right)$.

In addition, we compare SWAN and altimetry significant wave heights from different satellites (Figure 7). It can be seen that in whole, all satellites provide a similar errors. But there are a big differences in the small values of SWH: small SWH values from Envisat was rejected before (probably our preliminary filtering); SWH values near zero from Jason 1 have a lot of corresponding SWAN values in range $0.2-0.5 \mathrm{~m}$ (maximum of plot density) small SWH values from Jason 2 in good agreement with SWAN data.

Wave height measurements for 1996 were obtained from the buoy that was installed near Gelendzhik. They were analysed, filtered and used alongside with altimetry data for SWAN model verification. Model output point was $5 \mathrm{~km}$ away from the buoy. The nearest points of satellite altimetry data were added for comparison. They were chosen within borders of a rectangular area around the buoy with sides 55

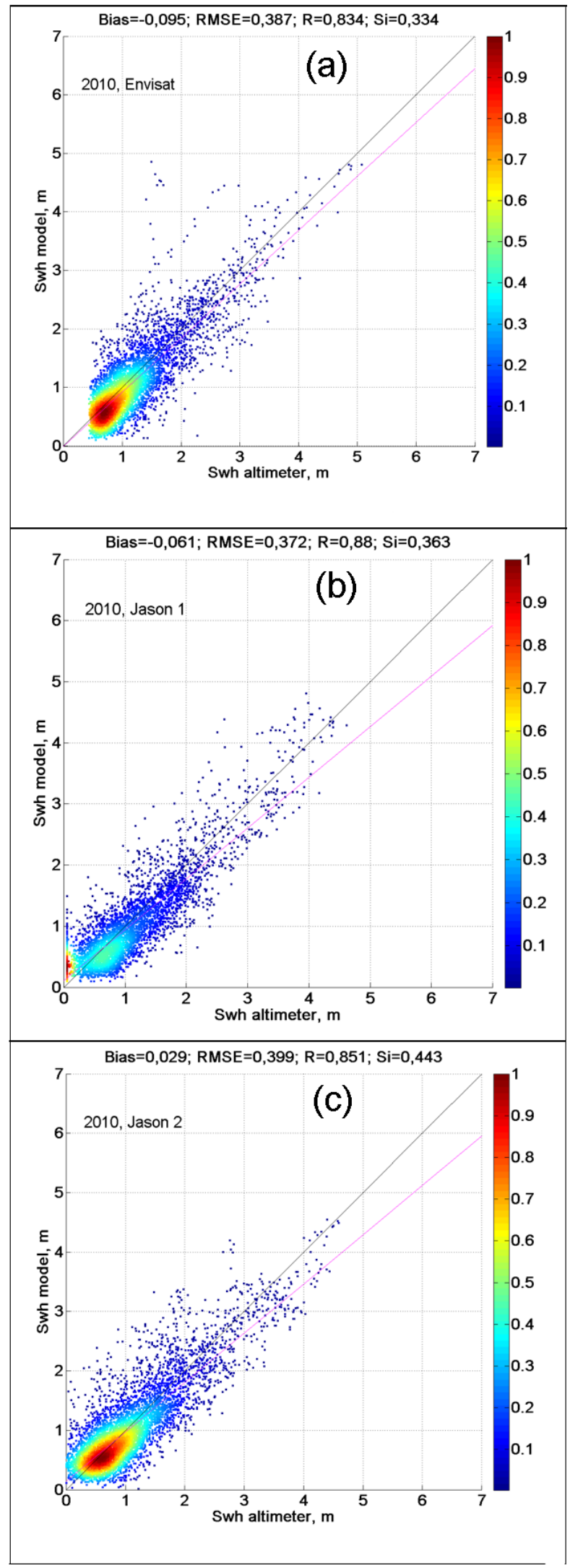

Figure 7. Comparison of SWAN and altimetry significant wave heights from: a) Envisat, b) Jason 1, c) Jason 2. 


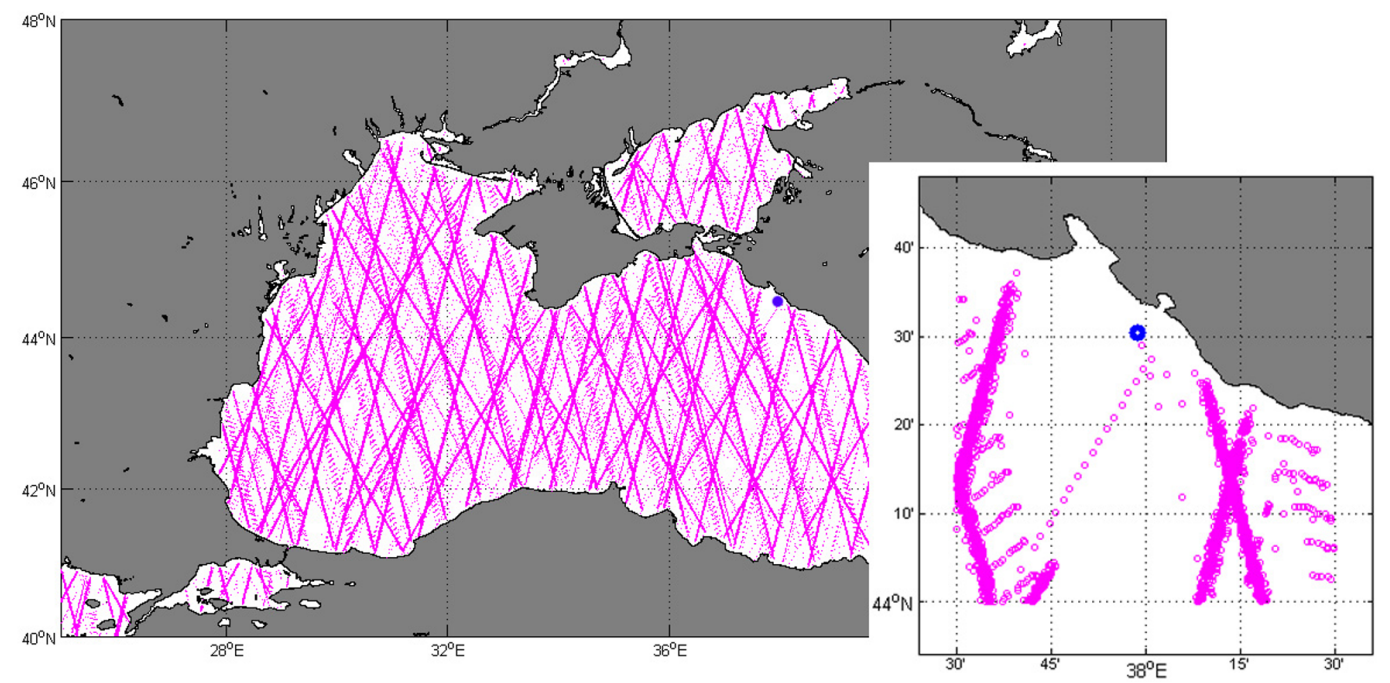

Figure 8. Gelendzhik buoy location and the closest altimetry tracks.

and $40 \mathrm{~km}$ long from south to north and from west to east respectively (Figure 8.

Comparison of the buoy data and SWAN simulation (the same configuration of model as in results for 2010-2012) is presented in Figure 9 and the nearest altimetry points are marked green. For the year 1996 we used data from ERS-1, ERS-2 and Topex satellites. Comparison of buoy and SWAN data demonstrates satisfying results: correlation exceeds 0.86 and the RMSE equals $0.3 \mathrm{~m}$. It can be seen that SWAN provides good data for the deep water.

The Gelendzhik buoy also measured average wave period. The data were compared with SWAN simulation and the results are presented in Figure 10. It shows that the model underestimates wave period within small values range and over-estimates it when period exceeds $6 \mathrm{~s}$.

Altimetry data can be used to retrieve wave periods as well. Using backscatter coefficient and the SWH data, presented in the measurement database, we applied common empirical algorithms for wave periods [Gommenginger et al.,
2003 Mackay et al.,2008 Quilfen et al.,2004. In addition, the physical model from [Badulin, 2014 was used. Wave periods T3 (periods corresponding to SWH) from buoy provide the slightly better coincide with altimetry data. Comparison of 1996 altimetry results and Gelendzhik buoy data shows that Quilfen et al. algorithm seems to give the best results. Unfortunately, the nearest points of altimetry data were far from buoy location and the total number or altimetry measurements was small. Therefore, this comparison is not important and we present only the results received via Quilfen et al. algorithm (Figure 11).

Possible cause of the model SWH underestimation Figure 4 is poor quality of input wind fields. We compared reanalysis wind velocity data and values provided by weather stations in Anapa and Novorossiysk. Error distribution for Anapa and Novorossiysk in 2010-2012 is shown in Figure 12 Figure 13 Increase in wind velocity modulus causes bias to grow almost linearly. However, this comparison is only applicable for two points and we cannot use this correction

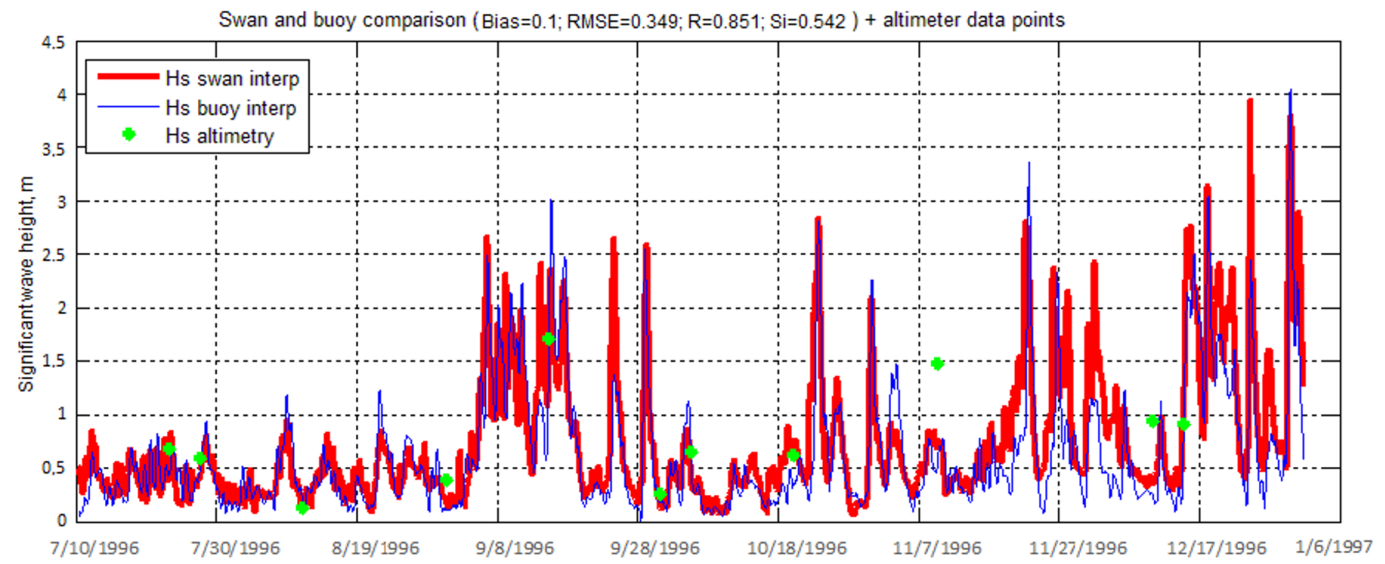

Figure 9. Comparison of SWH data from Gelendzhik buoy, SWAN simulation and the nearest altimetry points. 

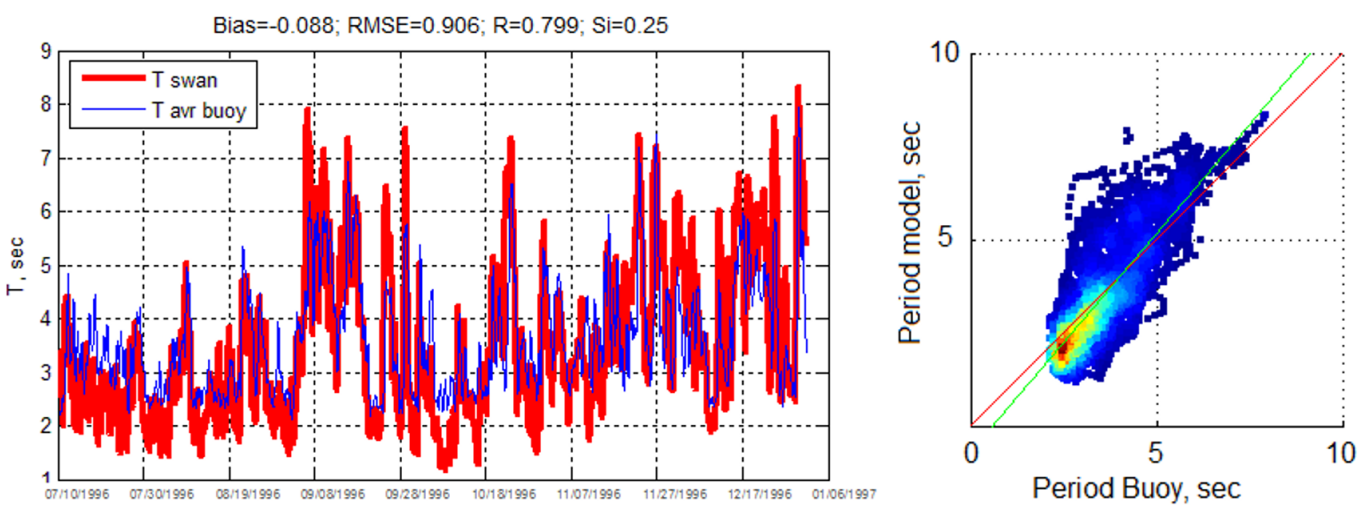

Figure 10. Comparison of SWAN average period and data from Gelendzhik buoy.

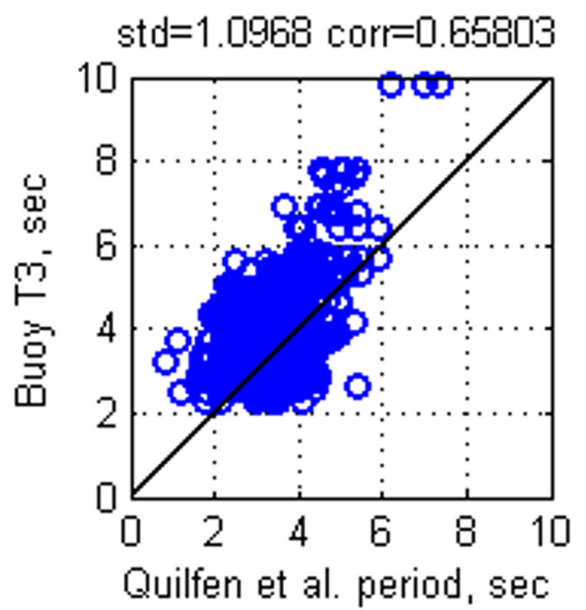

Figure 11. Comparison of altimetry periods and data from Gelendzhik buoy.

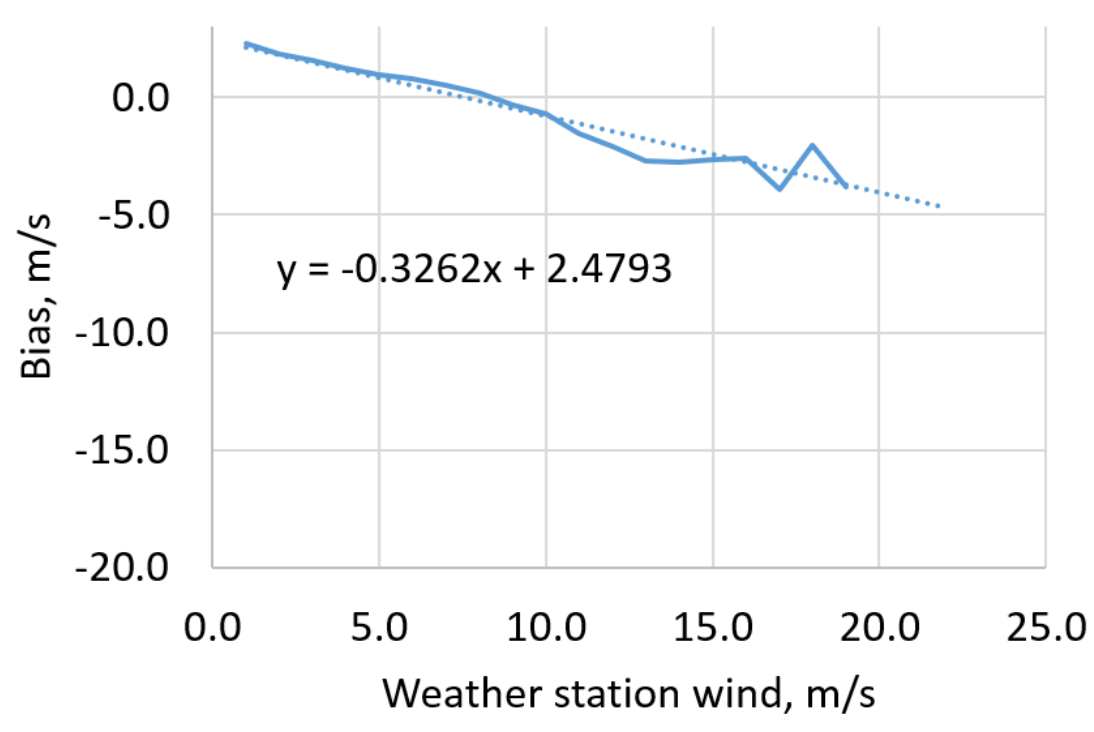

Figure 12. Error distribution for wind reanalysis data in Anapa 2010-2012. for total wind forcing field in the Black sea. One of the ways to fix this problem is to use all coastal weather station for total comparison with reanalysis data but quite possibly that error distribution will differ point-to-point and will not provide general correction equation. In [Van Vledder and Akpinar, 2015 the wind data from reanalysis and satellite altimetry were compared. Maps of spatial distribution of bias were compiled based on that comparison. They demonstrated inhomogeneity of said spatial distribution. Then the authors used the data of wind velocity bias to correct reanalysis results, but it did not improve the quality of the wave simulation.

Another way to solve this problem is to use mesoscale models of atmosphere within selected areas of the sea. This method has already been used in various studies [Myslenkov et al., 2016 Rusu, 2011 Toropov et al., 2012, however, we can not say that there is a sustainable improvement in wave simulation. We will continue to work in this direction in future studies and hope that it will help us improve the wind wave hindcast and forecast technologies.

\section{Conclusion}

The SWAN model was implemented for wave simulation in the Black sea, in particular, for regional application in the Tsemes bay. The NCEP/CFSR wind forcing data and unstructured mesh helped us obtain realistic wave fields.

The evaluation of the wave model quality was executed by means of satellite data in deep sea and direct wave measurements in shallow water. It is visible that wave hindcast has strong correlation with direct measurements -0.8 , the RMSE - 0.3. Comparison with satellite data provides even stronger correlation - 0.86 and the RMSE that equals 0.29. Comparison proves eligibility of SWAN model as a tool of significant wave height reanalysis.

Analysis of the error distribution in shallow water shows that in cases when the significant wave height values are less than $2-2.5 \mathrm{~m}$ wave model shows small bias $(0-0.3 \mathrm{~m})$, and for waves larger than $2.5 \mathrm{~m}$ bias is growing and the model starts to underestimate wave height. Possible cause of model 


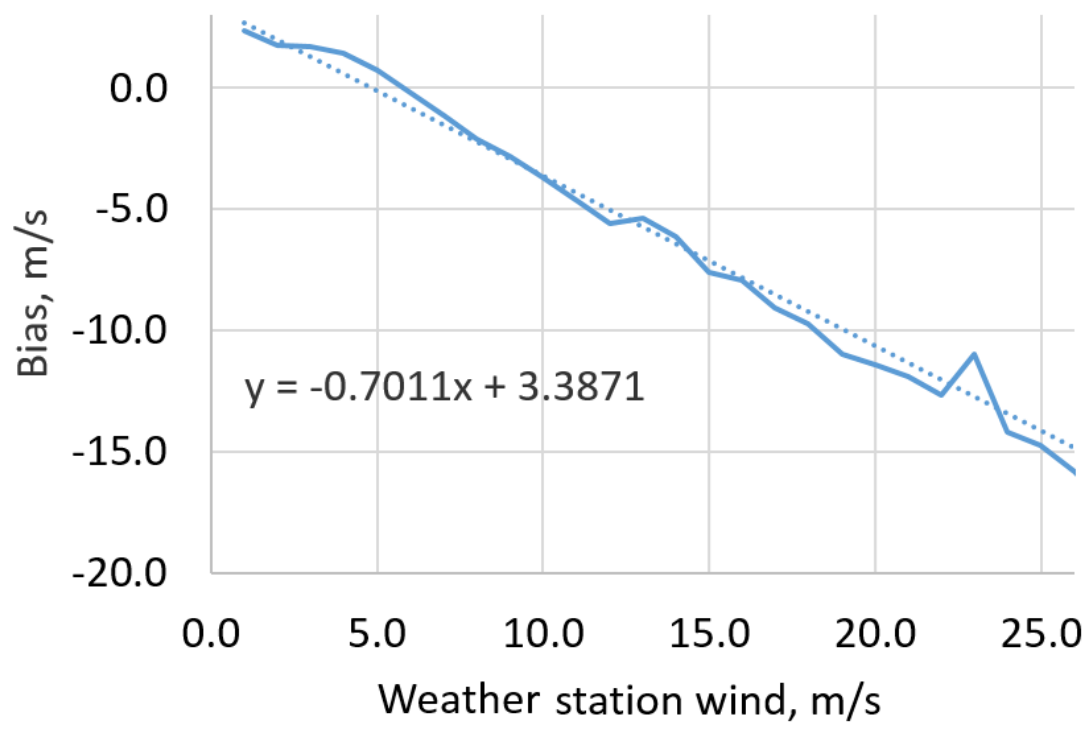

Figure 13. Error distribution for wind reanalysis data in Novorossiysk 2010-2012.

SWH underestimation is poor quality of input wind fields for high wind velocity values. It was confirmed by comparison of wind data from reanalysis and weather stations.

It can be inferred that the SWAN model simulation of wind waves in the Black Sea provides high quality results for both deep sea and shallow water.

Acknowledgments. Calculations of wave parameters made by S. Myslenkov and supported by a grant RFBR (project \# 16-0800829). Model verification based on satellite altimetry data was made by A. Chernyshova and supported by RFBR grant (\# 1405-31530).

\section{References}

Akpinar, A., G. Van Vledder, M. İ. Kömürcü, M. Özger (2012), Evaluation of the numerical wave model (SWAN) for wave simulation in the Black Sea, Continental Shelf Research, 50-51, 80-99.

Akpinar, A., S. Ponce de León (2016), An assessment of the wind re-analyses in the modelling of an extreme sea state in the Black Sea, Dynamics of Atmospheres and Oceans, 73, 61-75, doi:10.1016/j.dynatmoce.2015.12.002

Arkhipkin, V. S., et al. (2014), Wind waves in the Black Sea: results of a hindcast study, Natural Hazards and Earth System Science, Copernicus Gesellschaften (Germany), 14, No. 11, 2883-2897.

Arhipkin, V., et al. (2015), Assessing the potential of wave energy in coastal waters of Crimea peninsula, Al'ternativnaja Jenergetika $i$ Jekologija, No. 20, 25-35. (in Russian)

Badulin, S. I. (2014), A physical model of sea wave period from altimeter data, J. Geophys. Res. Oceans, 119, 856-869, doi:10.1002/2013JC009336

Booij, N., R. C. Ris, L. H. Holthuijsen (1999), A thirdgeneration wave model for coastal regions: 1 . Model description and validation, J. Geophys. Res., 104, 7649-7666.

Bukhanovskij, A. W., L. I. Lopatukhin, E. S. Chernisheva, A. M. Kolesov (2009), The storm on the Black Sea on 11 November 2007 and statistics of extreme storms of the sea,
Proceedings of the Russian Georgaphical Society, 141, 71-80. (in Russian)

Chelton, D. B., P. J. McCabe (1985), A review of satellite altimeter measurement of sea surface wind speed: With a proposed new algorithm, J. Geophys. Res., 90, 4707-4720.

Goldhirsh, J., E. Dobson (1985), A Recommended Algorithm for the Determination of Ocean Surface Wind Speed Using a Satellite-Borne Radar Altimeter, Report JHU/APL SIR-85-U005, App. Phys. Lab., Johns Hopkins University, Laurel, MD.

Gommenginger, C. P., M. A. Srokosz, P. G. Challenor, P. D. Cotton (2003), Measuring ocean wave period with satellite altimeters: A simple empirical model, Geophys. Res. Lett., 30, No. 22, 2150, doi:10.1029/2003GL017743

Janssen, P., S. Abdalla, H. Hersbsch, J.-R. Bidlot (2006), Error estimation of buoy, satellite, and model wave height data, Journal of Atmosphere and Oceanic Technology, 24, No. 9, 1665.

Ivonin, D. V., V. A. Telegin, P. V. Chernyshov, S. A. Myslenkov, S. B. Kuklev (2016), Possibilities of X-band nautical radars for monitoring of wind waves near the coast, Oceanology, 56 , No. 4, 591-600.

Kabatchenko, I. M., G. V. Matushevskij, M. V. Reznikov, M. M. Zaslavskij (2001), Modelirovanie vetra i voln pri vtorichnyh termicheskih ciklonah na Chernom more [Numerical modeling of wind and waves in a secondary cyclone at the Black sea], Meteorologija i Gidrologija, No. 5, 61-71. (in Russian)

Kos'yan, R. D., B. V. Divinsky, O. V. Pushkarev (1998), Measurements of parameters of wave processes in the open sea near Gelendzhik, The Eight Workshop of NATO TU-WAVES/ Black Sea p. 5-6, METU, Ankara, Turkey.

Lopatuhin, L. I., et al. (2006), Spravochnye Dannye po Rezhimu Vetra $i$ Volneniya Baltijskogo, Severnogo, Chernogo, Azovskogo i Sredizemnogo Morej, Rossijskij Morskoj Registr Sudohodstva, Saint Petersburg. (in Russian)

Mackay, E. B. L., et al. (2008), A parametric model for ocean wave period from Ku-band altimeter data, J. Geophys. Res., 113, C03029, doi:10.1029/2007JC004438

Medvedeva, A. Yu., V. S. Arkhipkin, S. A. Myslenkov, S. S. Zilitinkevich (2015), Wave climate of the Baltic Sea following the results of the SWAN spectral model application, Moscow University Bulletin. Series 5. Geography, No. 1, $12-22$.

Myslenkov, S. A., V. S. Arkhipkin (2013), The wind wave analysis in Tsemes Bay of the Black Sea using the SWAN model, 
Proceedings of the Hydrometcentre of Russia, No. 350, 58-67.

Myslenkov, S. A., A. A. Shestakova, P. A. Toropov (2016), Numerical simulation of storm waves near the Northeastern coast of the Black sea, Russian Meteorology and Hydrology, No. 10, 61-71.

Polonsky, A. B., V. V. Fomin, A. V. Garmashov (2011), Characteristics of wind waves of the Black Sea, Reports of the $\mathrm{Na}$ tional Academy of Sciences of Ukraine, 8, 108-112. (in Russian)

Quilfen, Y., B. Chapron, M. Serre (2004), Calibration/validation of an altimeter wave period model and application to TOPEX/Poseidon and Jason-1 altimeters, Marine Geodesy, 27, 535-549.

Roland, A., F. Ardhuin (2014), On the developments of spectral wave models: numerics and parameterizations for the coastal ocean, Ocean Dynamics, 64, No. 6, 833-846, doi:10.1007/s10236-014-0711-z

Rusu, E. (2011), Strategies in using numerical wave models in ocean/coastal applications, Journal of Marine Science and Technology, 19, 58-75.

Saha, Suranjana (2014), The NCEP Climate Forecast System Version 2, J. Climate, 27, 2185-2208, doi:10.1175/JCLI-D12-00823.1

Saleh Abdalla (2007), Ku-band radar altimeter surface wind speed algorithm, Proc. "Envisat Symposium 2007", Montreux, 23-27 April 2007, ESA SP-636, July 2007 p. 23-27, ESA, Switzerland.

Saleh Abdalla, Peter A. E. M. Janssen, Jean-Raymond Bidlot (2011), Altimeter Near Real Time Wind and Wave Products: Random Error Estimation, Marine Geodesy, 34, No. 3-4, 393-406, doi:10.1080/01490419.2011.585113

Stoliarova, E. V., S. A. Myslenkov (2015), High resolution wave forecast system for Kerch strait, Trudy Gidromete- orologicheskogo Nauchno-Issledovatel'skogo Centra Rossijskoj Federacii, No. 354, 24-35.

Surkova, G. V., V. S. Arkhipkin, A. V. Kislov (2013), Atmospheric circulation and storm events in the Black Sea and Caspian Sea, Centr. Eur. J. Geosci., 5, 548-559, doi:10.2478/ s13533-012-0150-7.

SWAN Team (2007),

SWAN Technical Documentation, $S W A N$ Cycle III version 40.51A, 98 pp., Delft University of Technology, Netherlands.

Toropov, P. A., S. A. Myslenkov, A. A. Shestakova (2012), Numerical simulation of Novorossiysk bora and related wind waves using the WRF-ARW and SWAN models, Russ. J. Earth Sci., 12, ES6001, doi:10.2205/2012ES000524

Valchev, N. N., E. V. Trifonova, N. K. Andreeva (2012), Past and recent trends in the western Black Sea storminess, Nat. Hazards Earth Syst. Sci., 12, 961-977, doi:10.5194/nhess12-961-2012

Van Vledder, G. Ph., Adem Akpinar (2015), Wave model predictions in the Black Sea: Sensitivity to wind fields, Applied Ocean Research, 53, 161-178.

Zelen'ko, A. A., et al. (2014), Sistema prognozirovanija vetrovogo volnenija v Mirovom okeane i morjah Rossii, $\mathrm{Tr}$. Gos. Okeanograficheskogo Instituta, 215, 90-101. (in Russian)

Zijlema, M. (2010), Computation of wind-wave spectra in coastal waters with SWAN on unstructured grids, Coast. Eng., 57, 267-277, doi:10.1016/j.coastaleng.2009.10.011

Stanislav Myslenkov, Lomonosov Moscow State University, Faculty of Geography, Department of Oceanology. (stasocean@gmail.com)

Anna Chernyshova, School of Mechanical Engineering Tel-Aviv University 